\title{
ANTI-ELASTASE, ANTI-COLLAGENASE AND ANTIMICROBIAL ACTIVITIES OF THE UNDERUTILIZED RED PITAYA PEEL: AN IN VITRO STUDY FOR ANTI-AGING APPLICATIONS
}

\author{
RAMYA VIJAYAKUMAR ${ }^{1}$, SITI SALWA ABD GANI ${ }^{1,2 *}$, NOR FADZILLAH MOKHTAR ${ }^{1,2}$ \\ ${ }^{1}$ Institut Penyelidikan Produk Halal, University Putra Malaysia, Putra Infoport, 43400 UPM Serdang, Selangor, Malaysia. ${ }^{2}$ Department of \\ Chemistry, Faculty of Science, University Putra Malaysia, 43400 UPM, Serdang, Selangor, Malaysia. E-mail: ssalwa.abdgani@gmail.com
}

Received: 09 April 2017, Revised and Accepted: 09 May 2017

\section{ABSTRACT}

Objective: To investigate the in vitro anti-elastase, anti-collagenase, and antimicrobial activities of the red pitaya peel extract for cosmetic application focusing on skin aging.

Methods: Extraction was performed by the reflux method for 103 minutes at $56^{\circ} \mathrm{C}$ with $82 \%$ aqueous ethanol solution and the red pitaya peel extract was evaporated using a rotary evaporator. Anti-elastase and anti-collagenase properties were evaluated using the drug discovery kits (neutrophil elastase colorimetric and matrix metalloproteinase- 1 colorimetric, respectively). The antimicrobial potential was analyzed using agar well diffusion method against 10 selected microorganisms, and the presence or absence of the inhibition zones was identified.

Results: The red pitaya peel extract exhibited remarkable inhibition percentage $87.62 \pm 0.05 \%$ and $96.92 \pm 0.02 \%$ for anti-elastase and anti-collagenase activities, respectively. Red pitaya peel extract showed significant inhibition against the Gram-positive Bacillus subtilis B29 with an inhibition zone diameter of $8.0 \pm 0.3 \mathrm{~mm}$.

Conclusion: The excellent anti-aging properties displayed by the underutilized red pitaya peel extract highlighted its potential as a natural source of anti-aging agent for cosmetic formulations.

Keywords: Skin aging, Anti-elastase, Anti-collagenase, Antimicrobial, Red pitaya peel.

(c) 2017 The Authors. Published by Innovare Academic Sciences Pvt Ltd. This is an open access article under the CC BY license (http://creativecommons. org/licenses/by/4. 0/) DOI: http://dx.doi.org/10.22159/ajpcr.2017.v10i8.19048

\section{INTRODUCTION}

Skin aging is regarded as one of the most common dermatological concerns in the modern society, and it is a complex inevitable process in human life. Extracellular matrix (ECM) is made up of proteoglycans interwoven with matrix metalloproteinase (MMP) including collagen, elastin, and fibronectin [1]. Collagen is the most abundantly found protein in the ECM and it plays an important role as an adherence to connective tissues, to ensure conducive cellular environments for development and morphogenesis [2-4]. Degeneration of this protein is crucial as it permits alteration in shape, cell migration or tissue desorption which are critically needed in tissue remodeling during growth, embryonic development or disease processes [4]. Elastase belongs to the chymotrypsin family proteases which regulates the breakdown of elastin. Elastase is capable of cleaving elastin, collagen, and fibronectin, along with other ECM proteins.

The most crucial combined functions of both elastase and MMPs following a wounding process are to discard the foreign proteins found within ECM during phagocytosis by neutrophils to ensure tissue repair process takes place under normal conditions [5]. Nevertheless, chronic ultraviolet (UV) exposure attributes to the denaturation of collagen and elastase in the dermis layer which eventually leads to the formation of wrinkles and photoaging of the skin. Excessive UV radiation causes a physical modification to the skin via complex pathways that result in the formation of reactive oxygen species (ROS) and secretion of both elastase and MMPs, respectively [6].

Pitaya or dragon fruit (Hylocereus sp) is a climbing vine cactus species which have successfully attained international recognition, both as an ornamental plant and as an economical fruit crop. Its fruit is regarded as the most beautiful in the Cactaceae family with a bright-red skin studded with green scales and white or red flesh with well dispersed small black seeds. Pitaya originates from the tropical forest regions of Mexico and Central and South America [7]. There are three varieties of pitaya, namely, white flesh pitaya with yellow peel (Selenicereus megalanthus), white flesh pitaya with red peel (Hylocereus undatus), and red flesh pitaya with red peel (Hylocereus polyrhizus) [8,9]. The red pitaya (H. polyrhizus) is being extensively cultivated in Malaysia, Thailand, Vietnam, Australia, Taiwan, and some other parts of the world [9].

Phytochemicals isolated from plants possess the potential to provide a substantially unexplored alternative for the invention of new drugs to be utilized in the cosmetics and pharmaceutical industries. The incorporation of plant-based bioactive compounds for the formulations of current skin care cosmetics is continually being emphasized due to the possible side effects that might be posed by the use of synthetic active ingredients. Previous studies on red pitaya peels focused more toward analyzing its antioxidant properties, but the information on its functional cosmetic properties are still scanty. In this study, for the first time, the anti-elastase and anti-collagenase properties of the red pitaya peel extract were evaluated to find out its suitability as a new source of anti-aging agent to be incorporated in the formulation of cosmetic and pharmaceutical products. Furthermore, the antimicrobial activity was also investigated.

\section{MATERIALS AND METHODS}

Materials

All the solvents and chemical reagents used in this study were of analytical grade and purchased from Malaysia Sigma-Aldrich. The spectrophotometric measurements were recorded on a double beam UV-visible spectrophotometry (UV-Vis) (Shimadzu UV-1800) instrument. 


\section{Red pitaya peel}

Freshly harvested red pitaya fruits (H. polyrhizus) were purchased from a fruit plantation located in Sepang, Selangor, Malaysia. Only fruits uniform in shape, size, and color were selected while excluding the blemished and diseased fruits. The fruits were washed to get rid of any adhered impurities on the surfaces and peeled manually to separate the pulp from the peels and cut into smaller size using a kitchen knife. The peels were then spread evenly onto a tray and left for the sun drying at an ambient air temperature about $30^{\circ} \mathrm{C}$ from 8 am to $5 \mathrm{pm}$ and packed in a plastic bag. The drying process was continued until the peels were completely dried. The dried peels were then ground to a fine powder using a commercial blender (MJ-220BP01A, Guangdong Beauty Life Electrical Appliances Manufacturing Co., Ltd., China). The powdered sample was carefully packed in an airtight polyethylene bag and stored in the dark at room temperature for further experiments.

\section{Extraction}

Approximately $20 \mathrm{mg}$ of the powdered red pitaya peels was added to $200 \mathrm{ml}$ of $82 \%$ ethanol and refluxed for 103 minutes at $56^{\circ} \mathrm{C}$. The mixture was then filtered using Whattman No. 1 filter paper, and the supernatant was concentrated using a rotatory evaporator (EYELA, N-N series, Tokyo, Japan) at $40^{\circ} \mathrm{C}$. The resulting extract was kept in the dark under refrigerated condition until further analysis.

\section{Determination of anti-elastase activity}

The elastase inhibition measurement was carried out using drug discovery kit (neutrophil elastase colorimetric and MMP-1 colorimetric) following the protocol as in Enzo Life Science [10]. For elastase inhibition assay, $20 \mu \mathrm{l}$ of tested sample was diluted with $65 \mu \mathrm{l}$ buffer solution containing $100 \mathrm{mM}$ HEPES, $500 \mathrm{mM} \mathrm{NaCl}$, and $0.05 \%$ Tween 20 in dimethyl sulfoxide (DMSO) in a 96-well plate. Elastatinal $(100 \mu \mathrm{M})$ was used as the control inhibitor. The neutrophil elastase enzyme (purified human neutrophil elastase, $2.2 \mu \mathrm{U} / \mu \mathrm{l}$ ) at $10 \mu \mathrm{l}$ was added to the diluted tested sample and incubated for 10 minutes at $37^{\circ} \mathrm{C}$. Later, $5 \mu \mathrm{l}$ substrate (MeOSuc-Ala-Ala-Pro-Val-pNA, $100 \mu \mathrm{M}$ ) was added to each well. The blank was prepared with $95 \mu \mathrm{l}$ buffer and $5 \mu \mathrm{l}$ of the substrate while the negative control was $10 \mu$ buffer and $5 \mu \mathrm{l}$ substrate with the addition of $20 \mu$ enzyme. The absorbance at $405 \mathrm{~nm}$ was measured using a microplate reader, and the percentage inhibition of elastase was calculated using the following equation.

$\%$ Inhibition $=\left(A_{0}-A_{1} / A_{0}\right) \times 100$

Where $A_{0}$ is the absorbance of the control, and $A_{1}$ is the absorbance of the sample extract.

The half maximal inhibitory concentration $\left(\mathrm{IC}_{50}\right.$ ) values were determined from plots of percent inhibition 50 versus inhibitor concentration and were calculated by linear regression analysis from the mean inhibitory values. Ascorbic acid was used as the positive control, and all the test were performed in triplicate.

\section{Determination of anti-collagenase activity}

The collagenase inhibition measurement was carried out using drug discovery kit (MMP-1 Colorimetric) following the protocol as in Enzo Life Science [11]. Briefly, for collagenase inhibition assay, $20 \mu \mathrm{l}$ of tested sample was diluted with $50 \mu \mathrm{l}$ buffer solution (50 mM HEPES, $10 \mathrm{mM}$

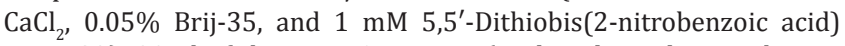
in DMSO). $20 \mu \mathrm{l}$ of the MMP-1 enzyme (Escherichia coli recombinant human MMP-1 catalytic domain, $153 \mathrm{mU} / \mu \mathrm{l}$ ) was added to each well before incubation at $37^{\circ} \mathrm{C}$ for 30 minutes. The substrate (thiopeptide, Ac-PLG-[2-mercapto-4-methyl-pentanoyl]-LG-OC2H5; $100 \mu \mathrm{M}$ ) at $10 \mu \mathrm{l}$ was added to each well. The blank was prepared with $90 \mu \mathrm{l}$ buffer and $10 \mu \mathrm{l}$ of the substrate while the negative control was $70 \mu \mathrm{l}$ buffer and $10 \mu \mathrm{l}$ substrate with the addition of $20 \mu \mathrm{l}$ enzyme. The absorbance at $412 \mathrm{~nm}$ was measured, and the percentage inhibition of collagenase was calculated using the following equation.

Inhibition $=\left(A_{0}-A_{1} / A_{0}\right) \times 100$
Where $A_{0}$ is the absorbance of the control, and is the absorbance of the sample extract.

The $\mathrm{IC}_{50}$ values were determined from plots of percent inhibition 50 versus inhibitor concentration and were calculated by linear regression analysis from the mean inhibitory values. Ascorbic acid was used as the positive control, and all the test were performed in triplicate.

\section{Determination of antimicrobial activity}

\section{Microorganisms}

The aqueous ethanolic extracts of red pitaya peel extract were tested for the antibacterial and antifungal activities against 10 indicator microorganisms including seven bacteria reference pathogens (E. coli E266, Staphylococcus aureus S276, Pseudomonas aeruginosa ATCC 15442, Methicillin-resistant S. aureus, Staphylococcus epidermidis S273, Bacillus subtilis B29, and Serratia marcescens S381), fungi (Aspergillus brasiliensis ATCC 16404) and two yeasts (Candida albicans 9002, and C. albicans C244) species [12].

Bacterial strains were grown in trypto-casein soy agar and incubated at $37^{\circ} \mathrm{C}$ for $24 \mathrm{hrs}$. Fungal species were grown on potato dextrose agar plate at $28^{\circ} \mathrm{C}$ for $72 \mathrm{hrs}$. C. albicans 9002 and C. albicans C244 were grown on sabouraud dextrose agar plate at $30^{\circ} \mathrm{C}$ for $48 \mathrm{hrs}$.

\section{Disc diffusion method}

The antibacterial activity of the red pitaya peel extract was performed using the agar disc diffusion method [13]. The suspensions of organisms were initially adjusted with sterile distilled water to a density equivalent to the 0.5 McFarland standards. $0.20 \mathrm{ml}$ of a $24 \mathrm{hrs}$ broth culture $\left(10^{6} \mathrm{cfu} / \mathrm{ml}\right)$ of the bacteria species was spread on the surface

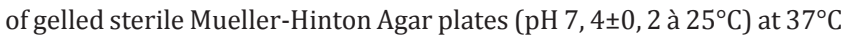
for $24 \mathrm{hrs}$ before use. Several colonies of a similar morphology of the respective bacteria were transferred into analytical profile index (API) suspension medium. The extract was prepared and then absorbed onto the sterile disc ( 20 and $30 \mu \mathrm{l})$, and the same volume of solvent was used as the negative control. The antibacterial activity was evaluated by measuring the diameter of the inhibition zones surrounding the discs. The experiment was performed in triplicate [14].

\section{Antifungal activity}

For screening the antifungal activity of the red pitaya peel extract, the agar disc diffusion method was used [15]. Three strains (A. brasiliensis, C. albicans, and C. albicans). All strains were first grown on Sabouraud chloramphenicol agar plate at $30^{\circ} \mathrm{C}$ for $18-24 \mathrm{hrs}$. Several colonies were transferred into API suspension medium and adjusted to 2 McFarland turbidity standards with a densimat. The inocula of the respective yeast were streaked into Sabouraud chloramphenicol agar plates at $30^{\circ} \mathrm{C}$ using a sterile swab and then dried. A sterile filter disc, diameter $5 \mathrm{~mm}$ (Whattman paper \# 3) was placed in the plate. An amount of $10 \mu \mathrm{l}$ of the extract was dropped on each paper disc $(10 \mathrm{mg} / \mathrm{disc})$. The treated Petri dishes were incubated at $30^{\circ} \mathrm{C}$ for $18-24 \mathrm{hrs}$. The antifungal activity was evaluated by measuring the diameter of the inhibition zones around the discs. The same volume of solvent was used as the negative control. Each experiment was carried out in triplicate, and the mean diameter of the inhibition zones was recorded [14].

\section{Statistical analysis}

The data were expressed as a mean \pm standard deviation of the three replicate determinations. One-way analysis of variance (ANOVA) was used to determine the differences between the means. ${ }^{*} \mathrm{p}<0.05$ was regarded as significant.

\section{RESULTS AND DISCUSSIONS}

\section{Anti-elastase activity}

The potential of red pitaya peel extract to aid in skin anti-aging properties was measured in terms of its ability to inhibit the elastase enzyme. The anti-elastase activity assay performed by taking ascorbic acid as a 
standard exhibited that red pitaya peels with the highest concentration of $1000 \mu \mathrm{g} / \mathrm{ml}$ possessed a high elastase inhibition percentage of $87.62 \pm 0.05 \%$, whereas the standard solution of ascorbic acid showed $93.55 \pm 0.11 \%$ as shown in Fig. 1 . The results of anti-elastase activities were classified into four groups: Highly active $\left(\mathrm{IC}_{50}<15.00 \mu \mathrm{g} / \mathrm{ml}\right.$ ), moderately active $\left(\mathrm{IC}_{50:} 15.01-50.00 \mu \mathrm{g} / \mathrm{ml}\right)$, weakly active $\left(\mathrm{IC}_{50:} 50.01\right.$ $100.00 \mu \mathrm{g} / \mathrm{ml}$ ), and inactive ( IC $_{50}>100.00 \mu \mathrm{g} / \mathrm{ml}$ ). The red pitaya peel extract showed moderately active elastase inhibition with $\mathrm{IC}_{50}$ of $(29.83 \pm 0.21) \mu \mathrm{g} / \mathrm{ml}$ while ascorbic acid showed high activity against elastase with $\mathrm{IC}_{50}$ of $(9.47 \pm 0.18) \mu \mathrm{g} / \mathrm{ml}$. Ascorbic acid was evidently the stronger inhibitor of the elastase enzyme taking into account it is a single molecule whereas the red pitaya peel extract is a mixture of various types of phytochemicals with different functionalities.

Aging is an inevitable process for all living organisms. During this process, ROS generation is increased which leads to mitochondrial damage in the cell. It was postulated that lifespan is determined by the rate of free radical damage to the mitochondria [16]. Besides, skin aging is a very complicated biological process which is influenced by various intrinsic and extrinsic aspects. The intrinsic factors are mainly due to the passage of time, whereas extrinsic factors are mainly caused by prolonged exposure to sunlight [17]. UV radiation accelerates the aging of skin that leads to the formation of peroxyl free radicals which break down to form malondialdehyde (MDA). MDA subsequently crosslinks and polymerizes collagen that results in the loss of skin elasticity and reducing the ability of the skin to hold water, which is expressed in the formation of the most obvious symptom of aging known as skin wrinkling [18]. Elevated levels of elastase activity give rise of multiple complications such as rheumatoid arthritis, cystic fibrosis, chronic obstructive airway disease, psoriasis, delayed wound healing, and premature skin aging with wrinkle formation. Elastase tends to cleave proteins, preferentially at the amino acid valine. Valine residues occur in a multitude of protein compounds, particularly in collagen and elastin fibrils. Furthermore, inflammatory processes are also affected by the decisive role of elastase enzyme [19-21].

The presence of phytochemicals in the plant extracts is highly correlated to the biological activities possessed by the plants [22]. The high elastase inhibition percentage displayed by red pitaya peel extract could largely be contributed by the presence of different bioactive such as vitamin $\mathrm{C}$, polyphenols, flavonoids, and betacyanins as reported by the previous studies [23,24]. In fact, vitamin C is considered as the most potent antioxidant and is capable of fighting against ROS to delay the aging process to protect the elastin and collagen fibers of the skin. The polyphenol and flavonoid compounds carry hydroxyl groups which are efficient in forming bonds with the carboxyl groups of the serine amino acid at the elastase enzyme's active site to alter the mechanism of the enzyme action. Consequently, elastase can no longer cleave the peptide bonds and this greatly helps in preventing the loss of skin elasticity and wrinkle formations [25]. Besides, phytopharmaceuticals rich herbal extracts, vitamins and antioxidant food supplement, which are well known for their excellent free radicals scavenging properties are accepted globally as the most promising source of topical treatments of skin aging which aids to restore the skin elasticity. In general, the antioxidants behave as anti-aging compounds in action because of the capacity to scavenge ROS, leaving a healthy effect on the skin. Since living systems have the capability to maintain homeostasis of ROS in cell, the human skin is protected from UV radiation through a complex antioxidant defense system comprising endogenous and exogenous antioxidant [26]. Therefore, topical application of skin care products with polyphenol-loaded plant extracts will protect the skin from harmful effects imposed by UV radiation that results in premature aging.

Plant by-products from the agro-industrial processing are often regarded as waste materials, and this leads to disposal problems that affect the environment. From the economic and environmental point of views, with the large availability and the composition that always rich in bioactive compounds, reutilization of these wastes for the production of beneficial products would be effective in terms of cost and environmental pollution [27]. Few studies have revealed that plant by-products such as coconut testa, rice bran, and cocoa pod also exhibited anti-elastase activities with percentage of inhibitions of $6.80 \pm 3.16 \%, 9.16 \pm 0.54 \%$, and $2.54 \pm 0.04 \%$, respectively $[28,29]$. These findings clearly emphasize that red pitaya peels possessed a much higher elastase inhibition properties which can be utilized as an efficient anti-aging agent in the formulation of plant-based cosmetic and pharmaceutical products. In fact, the anti-elastase activity exhibited by the red pitaya peel extract was comparable with ascorbic acid which is a widely known antioxidant used in cosmetic products as there was only a small difference between both of them.

\section{Anti-collagenase activity}

The anti-collagenase activity assay performed by taking ascorbic acid as a standard showed that red pitaya peels with the highest concentration of $1000 \mu \mathrm{g} / \mathrm{ml}$ possessed an excellent collagenase inhibition percentage of $96.92 \pm 0.02 \%$, whereas the standard solution of ascorbic acid showed $97.97 \pm 0.18 \%$ as shown in Fig. 2. The red pitaya peel extract showed moderate collagenase inhibition activity with $\mathrm{IC}_{50}$ of $(16.28 \pm 0.14) \mu \mathrm{g} / \mathrm{ml}$ while ascorbic acid was highly active against collagenase with $\mathrm{IC}_{50}$ of $(7.67 \pm 0.11) \mu \mathrm{g} / \mathrm{ml}$. The results showed that red pitaya peel extract is capable of inhibiting collagenase enzymes equally strong as the standard ascorbic acid, depicting its potential as a good source of anti-aging agent.

Produced from procollagen, collagen is the fundamental and the major molecular unit involved in the construction of human skin. Collagen

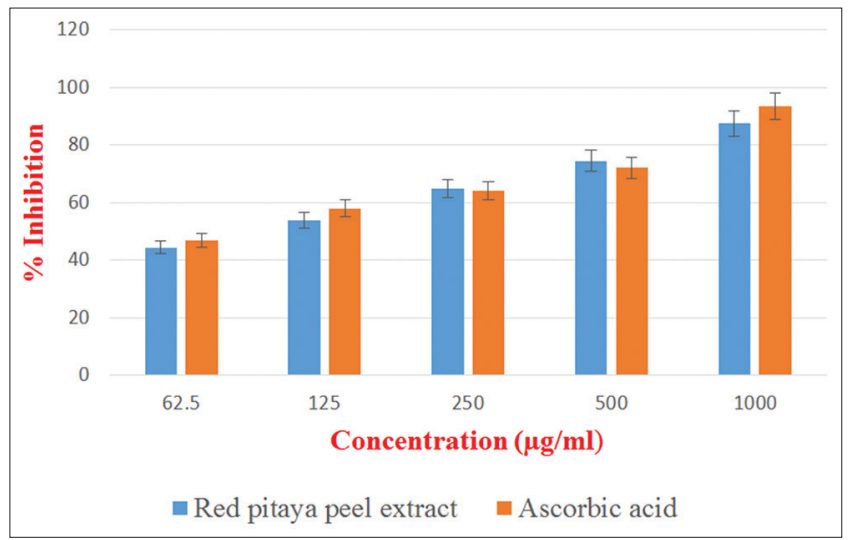

Fig. 1: The percentage of elastase inhibition of red pitaya peels extract and ascorbic acid with different concentrations (62.5$1000 \mu \mathrm{g} / \mathrm{ml})$. The values are means \pm standard deviation $(\mathrm{n}=3)$, and data were significant as $* \mathbf{p}<0.05$

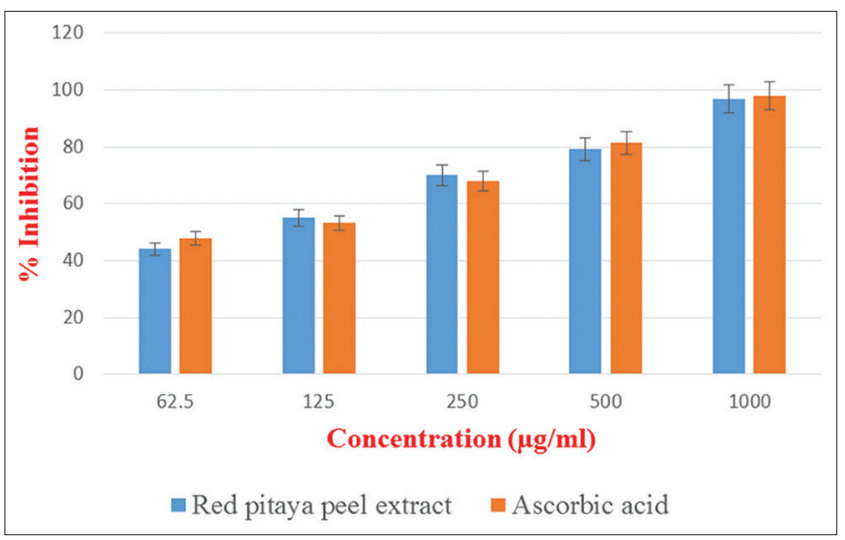

Fig. 2: The percentage of collagenase inhibition of red pitaya peels extract and ascorbic acid with different concentrations $(62.5-1000 \mu \mathrm{g} / \mathrm{ml})$. The values are means \pm standard deviation $(n=3)$, and data were significant as $* p<0.05$ 
is a protein that is commonly found in the connective tissues of the human body. Procollagen is synthesized by dermal fibroblasts under the effect of transforming growth factor- $\beta$ (TGF- $\beta$ ) and activator protein-1 (AP-1), where TGF- $\beta$ and AP-1 controls the formation and breakdown of collagen, respectively. The UV radiation encourages the MMPs enzymes secreted by keratinocytes, fibroblasts, and other cells to boost the collagen breakdown by AP-1 and also reduces the collagen synthesis $[30,31]$. Therefore, during photo-aging, connective tissues tend to break down [32-34]. During adulthood, approximately $1 \%$ decrease in collagen content per year occurs. However, this rate is much greater in the elderly people since older people have increased levels of MMPs [35]

MMPs are a group of zinc-containing proteinases. MMP-1 or also known as interstitial collagenase initiates the breakdown mostly of type I, II, and III collagens, which are the most abundant interstitial collagens in the dermis. The responsibility of MMP-2 is to break down type I-III, IV, and VII collagens in which the latter two are found in the highest amount in the dermal-epidermal junction. Apart from MMPs, elastase functions to digest elastin, another type of interstitial fibers in the skin. Reduction of both these structural fibers in the skin reduces the skin integrity and elasticity contributing to aging skin and wrinkle formation [36].

The presence of hydroxyl groups in the polyphenol compounds found in the red pitaya peel extract could interact with the backbone or other functional group side chain of collagenase. The hydrophobic interaction between the benzene ring of polyphenol and collagenase result in the conformational changes leading to malfunction of enzymes involved [37]. Another possible mechanism involves the $\mathrm{Zn}$ ion active site on collagenase. Collagenase contains a structural $\mathrm{Zn}$ ion at its active site which plays an important role to facilitate the interaction with an inhibitor [38]. Thus, polyphenol compounds may bind to the $\mathrm{Zn}$ ion active site and prevent the substrate from digesting the enzyme, and this mechanism could contribute to the excellent collagenase inhibition property of red pitaya peel extract [39].

\section{Antimicrobial activity}

Since ancient times, plants have been the main source of a therapeutic agent to treat different kinds of illness. Several plant-derived natural substances also exhibited antibacterial properties [40]. The in vitro antimicrobial activity potential of red pitaya peel extract employed against the selected microorganisms was accessed by the presence or absence of the inhibition zones. The results obtained revealed that red pitaya peel extract possessed a very weak antibacterial and antifungal activities. From the 10 tested pathogens, only with Gram-positive B. subtilis strain was most susceptible to the red pitaya peel extract with the pronounced activity of inhibition zone diameter of $8.0 \pm 0.3 \mathrm{~mm}$ at a concentration of $100 \mathrm{mg} / \mathrm{ml}$ while the remaining nine bacteria, fungi and yeast strains exhibited negative inhibitions. Previous literature reported that Grampositive bacteria displayed higher sensitivity toward plant extracts and oil when compared to Gram-negative bacteria due to the presence of hydrophobic lipopolysaccharide found in the outer membrane that aids in shielding them against the various agents $[41,42]$

However, Khalili et al. [43] reported that methanolic red pitaya peel extract showed a significant inhibitory effect against both $S$. epidermidis $(9.00 \pm 0.50 \mathrm{~mm})$ and $S$. aureus $(10.00 \pm 0.50 \mathrm{~mm})$. The choice of extraction solvent can be seen to influence the antimicrobial properties of the plant extracts obtained. In fact, methanol extraction was reported to possess significant antimicrobial properties than hexane and ethyl acetate whereas others reported that chloroform extraction yields better antimicrobial activity when compared to benzene and methanol. The polarity and solubility of extraction solvent contribute largely to the amount and nature of phytoconstituents being extracted out from the plant sample [44]. Since the red pitaya peel extract did not show strong activity toward a major portion of the tested microorganisms, a suitable preservative that is capable of providing both antibacterial and antifungal protections is necessary if the extract is to be incorporated in the cosmetic product formulations.
The combination of remarkable anti-elastase and anti-collagenase properties clearly showed the potential of red pitaya peel extract as a natural skin anti-ageing agent. The replacement of synthetic skin anti-aging chemicals with plant-derived phytochemicals will surely minimize the risk of various skin disorders brought about by the artificial active ingredients in commercial cosmetic products to a much greater extent. Not only that, the waste loads at the processing plant can be greatly reduced through the utilization of new or modified processing techniques or in-plant treatment and reuse of these agricultural wastes. Besides, technological advancements contribute greatly toward the development of a variety of processes to convert these waste materials into high-value bioproducts of excellent quality [45]. If this approach is successfully perceived, consumers' demand for nature-based skin aging products will be practicable. Besides, the usage of fruit and vegetable residues will not only be a driving force for the industries to accomplish a lower-waste agribusiness, but it will also increase the business profitability simultaneously [46].

\section{CONCLUSION}

On the whole, this study emphasized, for the first time, the anti-elastase and anti-collagenase activities of red pitaya peel extract which displayed remarkable inhibition percentage $87.62 \pm 0.05 \%$ and $96.92 \pm 0.02 \%$, respectively, and the results obtained imparted the benefits of red pitaya peels as a source of active ingredients with a broad range of pharmaceutical importance. The red pitaya peel extract showed a significant antimicrobial activity with $B$. subtilis strain only with a pronounced activity of inhibition zone diameter of $8.0 \pm 0.3 \mathrm{~mm}$. These findings, therefore, highlighted the promising potentials of red pitaya peels to be utilized in the cosmetic and pharmaceutical formulations as a natural source of phytochemical which offers excellent biological activities. This approach will be a safer, cheaper, and a more efficient alternative to the artificial skin anti-aging agents being used currently in the industries.

\section{REFERENCES}

1. Oikarinen A. Connective tissue and ageing. Int J Cosmet Sci 2004;26:107-8.

2. Masuda M, Murata K, Naruto S, Uwaya A, Isami F, Matsuda H. Matrix metalloproteinase-1 inhibitory activities of Morinda citrifolia seed extract and its constituents in UVA-irradiated human dermal fibroblasts. Biol Pharm Bull 2012;35(2):210-5.

3. Kim SH, Turnbull J, Guimond S. Extracellular matrix and cell signalling: The dynamic cooperation of integrin, proteoglycan and growth factor receptor. J Endocrinol 2011;209(2):139-51.

4. Yang HS, La WG, Bhang SH, Lee TJ, Lee M, Kim BS. Apatite-coated collagen scaffold for bone morphogenetic protein-2 delivery. Tissue Eng Part A 2011;17(17-18):2153-64

5. Thring TS, Hili P, Naughton DP. Anti-collagenase, anti-elastase and anti-oxidant activities of extracts from 21 plants. BMC Complement Altern Med 2009;9:27.

6. Laga AC, Murphy GF. The translational basis of human cutaneous photoaging: On models, methods, and meaning. Am J Pathol 2009;174(2):357-60.

7. Nerd A, Mizrahi Y. Reproductive biology of cactus fruit crops. Hortic Rev 1997;18:321-46.

8. Nerd A, Sitrita Y, Kaushika RA, Mizrahi Y. High summer temperatures inhibit flowering in vine pitaya crops (Hylocereus spp). Sci Hortic 2002;96(1-4):343-50.

9. Hoa TT, Clark CJ, Wadddell BC, Woolf AB. Postharvest quality of dragon fruit (Hylocereus undatus) following disinfesting hot air treatments. Postharvest Biol Technol 2006;41:62-9.

10. Enzo Life Sciences: Neutrophil Elastase Colorimetric Drug Discovery Kit. Available from: http://www.enzolifesciences.com/BML-AK497/ neutrophil-elastasecolorimetric-drugdiscovery-kit. [Last accessed on 2016 Feb 22].

11. Enzo Life Sciences. Matrix Metalloproteinase-1 (MMP-1) Colorimetric Drug Discovery Kit. Available from: http:/www.enzolifesciences.com/ BML-AK404/matrixmetalloproteinase-1-mmp-1-colorimetric-drugdiscovery-kit. [Last accessed on 2016 Dec 28].

12. Aouadhi C, Ghazghazi H, Hasnaoui B, Maaroufi A. Secondary metabolite, antioxidant and antibacterial activities of Teucrium polium 
L methanolic extract. Int J Agric Plant Prod 2013;4:1790-7.

13. Nilsson L. New rapid bioassay of gentamicin based on luciferase assay of extracellular ATP in bacterial cultures. Antimicrob Agents Chemother 1978;14(6):812-6.

14. Singh G, Kumar P. Antibacterial potential of alkaloids of Withania somnifera L. And Euphorbia hirta L. Int J Pharm Pharm Sci 2012;4:78-81.

15. Turney I, Cadirci BH, Nal D, Sukatar A. Antimicrobial activities of the extracts of marine algae from the coast of Urla (Izmir, Turky). Turk J Biol 2006;30:171-5.

16. Dua D, Srivastava NS. A study on antioxidant and anti-aging properties of few medicinal plants. Int J Pharm Pharm Sci 2016;8:344-7.

17. AssafH, Adly MA, Hussein MR. Aging and intrinsic aging: Pathogenesis and manifestations. In: Farage MA, Miller KW, Maibach HI, editors. Textbook of Aging Skin. $1^{\text {st }}$ ed. Berlin: Springer; 2010. p. 129-38.

18. Kim YH, Kim KS, Han CS, Yang HC, Park SH, Ko KI, et al. Inhibitory effects of natural plants of Jeju Island on elastase and MMP-1 expression. Int J Cosmet Sci 2007;29:487-8.

19. Siedle B, Hrenn A, Merfort I. Natural compounds as inhibitors of human neutrophil elastase. Planta Med 2007;73(5):401-20.

20. Siedle B, Gustavsson L, Johansson S, Murillo R, Castro V, Bohlin L, et al. The effect of sesquiterpene lactones on the release of human neutrophil elastase. Biochem Pharmacol 2003;65(5):897-903.

21. Klaas CA, Wagner G, Laufer S, Sosa S, Della Loggia R, Bomme U, et al. Studies on the anti-inflammatory activity of phytopharmaceuticals prepared from Arnica flowers. Planta Med 2002;68(5):385-91.

22. Lavanya J, Selvam S, Priya M, Jacintha P, Aradana M. Antioxidant and antimicrobial activity of selected medicinal plants against human oral pathogens. Int J Pharm Pharm Sci 2016;8:9

23. Nurul SR, Asmah R. Variability in nutritional composition and phytochemical properties of red pitaya (Hylocereus polyrhizus) from Malaysia and Australia. Int Food Res J 2014;21(4):1689-97.

24. Wu LC, Hsu HW, Chen YC, Chiu CC, Lin YI, Ho JA, et al. Antioxidant and anti-proliferative activities of red pitaya. Food Chem 2006;95:319-27

25. Iván G, Szabadka Z, Ordög R, Grolmusz V, Náray-Szabó G. Four spatial points that define enzyme families. Biochem Biophys Res Commun 2009;383(4):417-20.

26. SanderCS, ChangH,SalzmannS, MüllerCS,Ekanayake-MudiyanselageS, Elsner $\mathrm{P}$, et al. Photoaging is associated with protein oxidation in human skin in vivo. J Invest Dermatol 2002;118(4):618-25.

27. Panesar R, Kaur S, Panesar PS. Production of microbial pigments utilizing agro-industrial waste - A review. Curr Opin Food Sci 2015;1:70-6.

28. Jamaluddin A, Razak DL, Rashid NY, Sharifudin SA, Kahar AA, Saad AZ, et al. Effects of solid state fermentation by Monascus purpureus on phenolic content and biological activities of coconut testa and rice bran. J Teknol 2016;78(11-2):23-8

29. Karim AA, Azlan A, Ismail A, Hashim P, Gani SS, Zainudin BH, et al. Phenolic composition, antioxidant, anti-wrinkles and tyrosinase inhibitory activities of cocoa pod extract. BMC Complement Altern Med 2014;14:381.

30. Fisher GJ, Wang ZQ, Datta SC, Varani J, Kang S, Voorhees JJ. Pathophysiology of premature skin aging induced by ultraviolet light.
N Engl J Med 1997;337(20):1419-28.

31. Varani J, Warner RL, Gharaee-Kermani M, Phan SH, Kang S, Chung $\mathrm{JH}$, et al. Vitamin A antagonizes decreased cell growth and elevated collagen-degrading matrix metalloproteinases and stimulates collagen accumulation in naturally aged human skin. J Invest Dermatol 2000;114(3):480-6

32. Fisher GJ, Datta SC, Talwar HS, Wang ZQ, Varani J, Kang S, et al. Molecular basis of sun-induced premature skin ageing and retinoid antagonism. Nature 1996;379(6563):335-9.

33. Chung JH, Seo JY, Choi HR, Lee MK, Youn CS, Rhie G, et al. Modulation of skin collagen metabolism in aged and photoaged human skin in vivo. J Invest Dermatol 2001;117(5):1218-24.

34. Chung JH, Seo JY, Lee MK, Eun HC, Lee JH, Kang S, et al. Ultraviolet modulation of human macrophage metalloelastase in human skin in vivo. J Invest Dermatol 2002;119(2):507-12.

35. Seo JY, Chung JH. Thermal aging: A new concept of skin aging. J Dermatol Sci 2006;2:S13-22.

36. Chanvorachote P, Pongrakhananon V, Luanpitpong S, Chanvorachote B, Wannachaiyasit S, Nimmannit U. Type I pro-collagen promoting and anti-collagenase activities of Phyllanthus emblica extract in mouse fibroblasts. J Cosmet Sci 2009;60(4):395-403.

37. Madhan B, Krishnamoorthy G, Rao JR, Nair BU. Role of green tea polyphenols in the inhibition of collagenolytic activity by collagenase. Int J Biol Macromol 2007;41(1):16-22.

38. Bigg HF, Clark IM, Cawston TE. Fragments of human fibroblast collagenase: Interaction with metalloproteinase inhibitors and substrates. Biochim Biophys Acta 1994;1208(1):157-65.

39. Mc Donald M, Mila I, Scalbert A. Precipitaion of metal ions by plant polyphenols: Optimal conditions and origin of precipitation. J Agric Food Chem 1996;44:599-606.

40. Sen A, Batra A. Evaluation of antimicrobial activity of different solvent extracts of medicinal plant: Melia azedarach L. Int J Curr Pharm Res 2012;4:67-73.

41. Ullah MO, Haque M, Urmi KF, Zulfiker AH, Anita ES, Begum M, et al. Anti-bacterial activity and brine shrimp lethality bioassay of methanolic extracts of fourteen different edible vegetables from Bangladesh. Asian Pac J Trop Biomed 2013;3(1):1-7.

42. Bhattacharya S, Zaman MK, Haldar PK. Antibacterial activity of stem bark and root of Indian Zanthoxylum nitidum. Asian J Pharm Clin Res 2009;2(1):30-4.

43. Khalili RA, Abdullah AB, Manaf AA. Antibacterial activity of flesh and peel methanol fractions of red pitaya, white pitaya and papaya on selected food. Int J Pharm Pharm Sci 2012;330:87-95.

44. Krishna VV, Kumar KG, Pradeepa K, Kumar SR. Antibacterial activity of ethanol extract of Musa paradisiaca CV. Puttable and Musa acuminate CV. Grand naine. Asian J Pharm Clin Res 2013;6(2):169-72.

45. Ayala-Zavala JF, Vega-Vega V, Rosas-Domínguez C, Palafox-Carlos H, Villa-Rodriguez JA, Wasim Siddiqui MD, et al. Agro-industrial potential of exotic fruit byproducts as a source of food additives. Food Res Int 2011;44(7):1866-74.

46. Makris DP, Boskou G, Andrikopoulos NK. Recovery of antioxidant phenolics from white vinification solid by-products employing water/ ethanol mixtures. Bioresour Technol 2007;98(15):2963-7. 